\title{
Pre- and post-operative evaluation: percentages of circulating myeloid-derived suppressor cells in rectal cancer patients
}

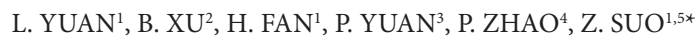 \\ ${ }^{1}$ Department of Oncology, The First Affiliated Hospital of Zhengzhou University, Zhengzhou, Henan, P.R. China; ${ }^{2}$ Central Laboratory, The \\ Affiliated Cancer Hospital of Zhengzhou University, Zhengzhou, Henan, P.R. China; ${ }^{3}$ Department of Surgery, The Affiliated Cancer Hospital \\ of Zhengzhou University, Zhengzhou, Henan, P.R. China; ${ }^{4}$ Department of Oncology, The First Affiliated Hospital of Zhejiang University, \\ Hangzhou, Zhejiang, PR, China; ${ }^{5}$ Department of Pathology, Oslo University Hospital and Clinical Institute, Faculty of Medicine, University \\ of Oslo, Oslo, Norway
}

${ }^{*}$ Correspondence: zhenhe.suo@medisin.uio.no

Received March 31, 2014 / Accepted June 2, 2014

\begin{abstract}
This study aims to explore whether pre-operative or post-operative percentages of circulating myeloid-derived suppressor cells (MDSC) have any correlations with clinicopathological parameters in patients with rectal cancer and have any predictive values for local recurrence and disease free survival. Lin $/$ HLADR/CD $11 \mathrm{~b}^{+} / \mathrm{CD} 33^{+}$MDSCs were analyzed in the study. Blood samples before and after surgery were measured by flow cytometry to determine the MDSC percentages. Plasma arginase I levels were analyzed using an enzyme-linked immunosorbent assay. Digital rectal examination, abdominal ultrasonography, or computed tomography was performed every three months after surgery to monitor local recurrence. Prior to surgery, cancer patients presented with higher levels of circulating MDSC compared to healthy controls (medians of $3.89 \%$ and $0.57 \%$, respectively). Seven days after operation, we observed an immediate increase in MDSC followed by a downtrend. Local recurrence was observed in 11 of 41 patients (26.8\%) with stage I/II cancer and 11 of 23 patients $(47.8 \%)$ with stage III cancer. Significantly higher percentages of MDSC were observed in patients who had local recurrence versus patients without local recurrence. Multivariate analysis further verified that the pre-operative level of MDSC was significantly associated with local recurrence $(P=0.038)$. Therefore, our results indicate that pre-operative percentage of MDSC appears to be a reliable prognostic marker for local recurrence and poor disease free survival in rectal cancer patients with curative resection.
\end{abstract}

Key words: myeloid-derived suppressor cells, rectal cancer, plasma arginase I, local recurrence, disease free survival

Rectal cancer is the fifth most common malignant tumor in adults worldwide [1]. Although the clinical management for rectal cancer has become increasingly multi-modal, surgery remains a cornerstone curative therapy in rectal cancer [2, 3]. However, surgery can have detrimental effects on patient's physical and psychological well-being at the same time to eradicate the tumor by the greatest extent. Therefore, exploring novel therapies in combination with surgery is of benefit to clinical care of rectal cancer patients.

The prognosis of rectal cancer depends strongly on clinical stage upon diagnosis, although this is not the sole determinant of treatment. Recently, it has been reported that components of the immune system can influence cancer patient outcome $[4,5]$.
Myeloid-derived suppressor cells (MDSC), as important regulatory immune cells, play a significant role in the development of immune tolerance in progression of cancer [6]. In addition, it has been reported that MDSC are also associated with autoimmunity and inflammation [7]. MDSC are a heterogeneous population of myeloid origin cells with the ability to suppress T cells [8-10]. In humans, MDSCs are most commonly defined as express the common myeloid marker $\mathrm{CD} 33^{+} \mathrm{CD} 14{ }^{-} \mathrm{CD} 11 \mathrm{~b}^{+}$cells but lack the expression of markers of mature myeloid and lymphoid cells, and lack the expression of the MHC-class-II molecule HLA-DR[11,12]. While suppressive myeloid cells were first described more than 20 years ago in cancer patients [13-15], the clinical significance of MDSC in human malignancies is still poorly understood. 
In this study, a population of Lin-HLA-DR-CD $33^{+} \mathrm{CD} 11 \mathrm{~b}^{+}$ cells were readily detected in fresh whole blood and defined as MDSC. We examined circulating MDSC in rectal cancer patients before and after tumor resection, and further studied the association of pre-operative and post-operative circulating MDSC percentages with tumor stage, metastasis, recurrence, and disease-free survival. Prior to surgery, cancer patients were presented with higher levels of circulating MDSC compared to healthy controls, circulating MDSC levels correlate with cancer stage, tumor volume, local recurrence, there was a transient surges in MDSC after tumor resection, then showed a downtrend. Multivariate analysis further verified that the pre-operative level of MDSC appears to be a good prognostic marker for local recurrence and poor disease free survival in rectal cancer patients with curative resection.

\section{Patients and methods}

Ethics statement. This study was approved by The Institute Ethical Committee of The Affiliated Cancer Hospital of Zhengzhou University, China. Written informed consents were obtained from all patients.

Table1. Patient characteristics.

\begin{tabular}{|c|c|c|}
\hline Variable & Category & Numbers \\
\hline Total patients (n) & & 64 \\
\hline Median age in years (range) & & $62(38-76)$ \\
\hline \multirow[t]{2}{*}{ Gender } & male & 45 \\
\hline & female & 19 \\
\hline \multirow[t]{2}{*}{ AJCC stage (2010) } & $\mathrm{I} / \mathrm{II}$ & 41 \\
\hline & III & 23 \\
\hline \multirow[t]{2}{*}{ Histologic differentiation } & well/moderate & 45 \\
\hline & poor & 19 \\
\hline \multirow[t]{4}{*}{ Post-operative complications } & & $8 / 64$ \\
\hline & anastomotic leakage & 5 \\
\hline & anastomotic bleeding & 1 \\
\hline & anastomotic inflammation & 2 \\
\hline \multirow{4}{*}{$\begin{array}{l}\text { Subsequent treatment status } \\
\text { (after operation) }\end{array}$} & none & 3 \\
\hline & chemotherapy & 31 \\
\hline & chemoradiation & 18 \\
\hline & $\begin{array}{l}\text { chemotherapy and biologi- } \\
\text { cal agent }\end{array}$ & 12 \\
\hline \multirow{4}{*}{$\begin{array}{l}\text { Subsequent treatment status } \\
\text { (after recurrence) }\end{array}$} & chemotherapy & 6 \\
\hline & chemoradiation & 7 \\
\hline & $\begin{array}{l}\text { chemotherapy and biologi- } \\
\text { cal agent }\end{array}$ & 6 \\
\hline & biological agent & 3 \\
\hline \multirow[t]{3}{*}{ Weight loss } & none & 27 \\
\hline & $\leq 10 \%$ & 26 \\
\hline & $>10 \%$ & 11 \\
\hline \multirow[t]{3}{*}{ Smoking status } & current & 39 \\
\hline & ex-smoker & 5 \\
\hline & never & 20 \\
\hline
\end{tabular}

Patients. Patients receiving other therapies such as chemotherapy and/or radiotherapy prior to surgery and patients lacking post-operative follow up were excluded from this study. Sixty-four patients were qualified and enrolled in this study. All patients with primary rectal cancer were operated on between January 2008 and December 2008 at the Department of Surgery, The Affiliated Cancer Hospital of Zhengzhou University, China. Whole blood samples were collected from each patient before and after operation. The clinical stage was classified according to the American Joint Committee on Cancer (AJCC) Staging Manual, Seventh Edition (2010). The median age of patients in this study was 62 years (range $38-76$ years). Thirty-four healthy donors with similar gender and age distribution served as controls (median age 58.7 years). The following clinicopathological characteristics were recorded: age, sex, weight loss, histological grade, carcinoembryonic antigen (CEA) level, smoking status at the time of blood sample collection, and subsequent systemic treatment (Table 1).

Flow cytometry for myeloid-derived suppressor cells. Fresh venous blood was collected from patients or healthy donors with a heparin sodium anticoagulation tube and used for quantitative MDSC study. For in vitro functional MDSC study, peripheral blood mononuclear cells (PBMC) from fresh venous blood were used. Percentages of circulating HLA-DR-Lin ${ }^{-} D 33^{+} \mathrm{CD} 11 \mathrm{~b}^{+}$MDSC were determined using flow cytometry. Blood samples were collected at one day before operation (BL), and after operation (day 7, day 14, and day 21 after operation). Specific antibodies against Lineage-FITC (Biolegend), HLA-DR-PerCP-cy5.5 (BD Pharmingen $^{\mathrm{ms}}$ ), CD33-PE (BD Pharmingen ${ }^{\mathrm{Tm}}$ ), CD11b/Mac1-APC (BD Pharmingen ${ }^{\mathrm{m}}$ ) were used. Fresh venous blood samples labeled with corresponding fluorochrome conjugated non-immune isotypes were taken as negative controls. Briefly, $30 \mu \mathrm{L}$ of blood was mixed with $5 \mu \mathrm{L}$ of each antibody and was incubated on ice for $20 \mathrm{~min}$ in dark. After incubation, each sample was mixed with $2 \mathrm{~mL}$ of $1 \mathrm{X}$ lysis buffer (BD Biosciences) and incubated at room temperature for $15 \mathrm{~min}$. Samples were washed with FACS buffer (5\% BSA in PBS, $0.09 \%$ sodium azide), and then fixed with $1 \%$ formalin at room temperature for $20 \mathrm{~min}$ before washed with FACS buffer again. The pellets were resuspended in $300 \mu \mathrm{L}$ of FACS buffer and stored at $4^{\circ} \mathrm{C}$ until analysis. Flow cytometry was performed with a BD FACS Aria II flow cytometer and data were analyzed with FlowJo software.

In vitro suppression assay. $\mathrm{PBMC}$ from five healthy donors and five patients with stage III rectal cancer were isolated by Ficoll density gradient from $20 \mathrm{~mL}$ of whole blood. HLA-DR Lin ${ }^{-} \mathrm{CD} 33^{+} \mathrm{CD} 11 \mathrm{~b}^{+}$MDSC and autologous $\mathrm{CD}^{+} \mathrm{T}$ cells were sorted by FACS Aria II cell sorting system (BD). Sixty thousand T cells labeled with $2.5 \mu \mathrm{M}$ CFSE (Carboxyfluorescein succinimidyl ester, Invitrogen Molecular Probe) were cocultured with (T with MDSC) or without autologous MDSC (T without MDSC) at 2:1 ratios in the absence or presence of soluble anti-CD3/CD28 (5 $\mu \mathrm{g} / \mathrm{mL})$ antibodies and IL-2 (1000 units $/ \mathrm{mL}$ ). Co-cultures were conducted in duplicate. After 4 
days, cells were stained for CD3-APC as a surface marker, and $\mathrm{T}$ cell proliferation was analyzed by flow cytometry [16-20]. Mean fluorescence intensity (MFI) of CD3 was calculated in the $\mathrm{CFSE}^{+} / \mathrm{CD}^{+}$cell gate. $\mathrm{CFSE}^{\text {low }}$ cells represent proliferating $T$ cells and CFSE ${ }^{\text {high }}$ cells represent the nondividing, suppressed $\mathrm{T}$ cell population.

Elisa. Plasma arginase I serum levels in cancer patients $(\mathrm{N}=64$, pre- and post-operation) and healthy donors $(\mathrm{N}=34)$ were analyzed using an enzyme-linked immunosorbent assay (ELISA) kit (BioVendor, UK). Hemolyzed samples were excluded. All serum samples were assayed in duplicate and the mean absorbance was calculated from the standard curve. In order to measure the levels of arginase activity from isolated HLA-DR-Lin $\mathrm{CD}^{3} 3^{+} \mathrm{CD} 11 \mathrm{~b}^{+}$MDSC, PBMC were isolated from $20 \mathrm{~mL}$ of whole blood taken from 10 healthy donors and 10 rectal cancer patients with stage III at different time points in their course and frozen in liquid nitrogen in a medium of $90 \%$ human $\mathrm{AB}$ serum plus $10 \%$ dimethylsulfoxide. Frozen PBMC were recovered and cultured in a culture medium of RPMI 1640 plus 10\% human AB serum (Gibco, Life technologies, USA) for 24 hours before MDSC were sorted and cultured in a culture medium without any stimulation for $48 \mathrm{hrs}$. Then supernatants were harvested for arginase activity investigation with the quanti-chrom arginase assay kit (BioAssay Systems, Hayward, CA) [10].

Nitric oxide (NO) production. NO content in plasma was measured following the manufacturer's protocol (Biovision, Milpitas, CA, USA). NO content in the culture supernatants from isolated MDSC of 10 healthy donors and 10 patients were also measured. An equal volume of plasma or supernatant $(100 \mu \mathrm{L})$ and Greiss reagent were mixed and incubated at room temperature for $10 \mathrm{~min}$. Absorbance at $550 \mathrm{~nm}$ was measured using a microplate reader (Bio-Rad, Hercules, CA). Nitrite concentrations were calculated from a standard curve generated with serial dilution of $0.25 \mathrm{mM}$ sodium nitrite $[10,16]$.

Statistical analysis. Continuous variables were summarized as medians and ranges. Correlation between circulating MDSC percentages and clinicopathological features were examined by the Mann Whitney U test. Spearman's rank correlation coefficiency was used to compare ordinal and continuous variables. Differences in pre- and post-operative circulating MDSC percentages were examined by the Friedman and Kendall test. Cumulative survival time was calculated by the Kaplan-Meier method and analyzed by the log-rank test. Univariate and multivariate analyses were performed based on the Cox proportional hazards regression model. Survival was determined from the period of surgical operation to occurrence of death / relapse or the last follow-up date. For all analyses of survival, the cut off value for definition of subgroups was the median value. Statistical significance in this study was set as $P<0.05$. All reported $P$-values were performed as two-sided and analyses were performed with SPSS statistical package (SPSS version 13.0 for Windows).

\section{Results}

Association of pre-operative MDSC percentages with clinical and pathological characteristics. To determine the percentages of MDSC in patients, fresh whole blood was incubated with a mixture of antibodies against CD33-PE, Lin-FITC, HLA-DR-PerCP-cy5.5, and CD11b/Mac-1-APC. Acquired cells were first gated based on the expression of HLADR-Lin. Within this population the fraction of cells expressing $\mathrm{CD}_{3}{ }^{+} \mathrm{CD} 11 \mathrm{~b}^{+}$were determined. Therefore, MDSC were defined as $\mathrm{CD}_{3} 3^{+} \mathrm{CD} 11 \mathrm{~b}^{+} \mathrm{HLA}-\mathrm{DR} \mathrm{Lin}^{-}$cells. The percentage of circulating MDSC was examined in all of the 64 patients before operation. The median percentage of circulating MDSC was $3.89 \%$ (range: $0.87 \%$ to $9.22 \%$ ), which was statistically higher than that in healthy controls (median $=0.57 \%$, range: $0.32 \%$ to $1.21 \%), P<0.0001$, Fig. 1A. The association of MDSC percentage with clinicopathological parameters was further analyzed in cancer patients. There was no significant correlation between MDSC percentage and histological grade $(P=0.2547$, Fig. 1B). However, a significant increase of MDSC percentage was observed in stage III patients compared to stage I/II patients (Fig. 1C), albeit there was MDSC percentage overlap between the two groups of patients. The median percentage of MDSC was $3.56 \%$ (range: $0.87 \%$ to $5.22 \%$ ) in stage I/II patients, whereas the median percentage was $4.56 \%$ (range: $1.58 \%$ to $9.22 \%$ ) in stage III patients, $P=0.0005$. In addition, it was also discovered that the MDSC percentages were positively correlated with tumor volume $(P<0.0001$, Fig.1D).

Tumor resection causes dramatic transient increase in MDSC. MDSC percentages were determined in all patients at the time of both pre-operation and post-operation. The median MDSC detection rates were $3.89 \%$ (range: $0.87 \%$ to 9.22\%), $7.1 \%$ (range: $2.34 \%$ to $14.34 \%$ ), $4.39 \%$ (range: $1.89 \%$ to $7.32 \%$ ), and $2.21 \%$ (range: $0.56 \%$ to $4.24 \%$ ) at one day before operation (BL) and day 7, day 14, and day 21 after surgery, respectively. There was a dramatic increase in MDSC detection at day 7 after operation, and then decreased at day 14 and day 21 (Fig. 1E). This represents a 1.83-fold increase in the proportion of circulating MDSC at day 7 after operation compared to BL. The circulating MDSC percentages in patients at day 7 after operation were significantly higher than that before operation, $P<0.0001$. Representative MDSC flow diagrams from one healthy donor and a patient from whole blood at different time after surgery are shown in Fig. 2.

MDSC from rectal cancer patients suppress $\mathrm{T}$ cell activity. Due to the phenotypic heterogeneity of MDSC, it is essential to characterize their immune-suppressive activity in patients. Representative flow diagrams from one healthy donor and a patient of MDSC in PBMC at different time after surgery are shown in Fig. 2A. T cells labeled with CFSE were cultured with or without autologous MDSC at a ratio of $2: 1$ in the absence or presence of CD3/CD28 antibodies and IL-2 for 4 days. Flow cytometric analysis demonstrated that $\mathrm{T}$ cells from cancer patients and healthy controls had similar activity in the presence of stimulation. No inhibitory 
A

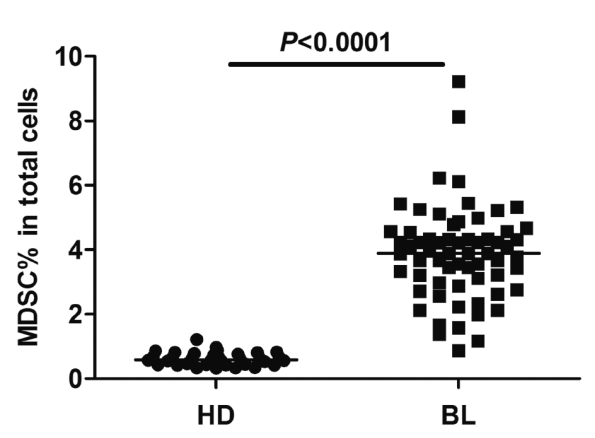

\section{B}

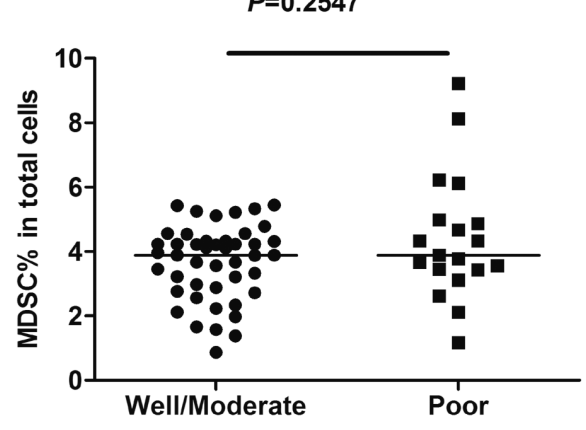

C

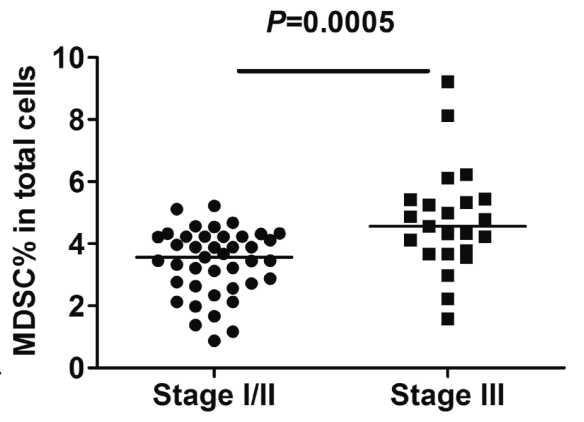

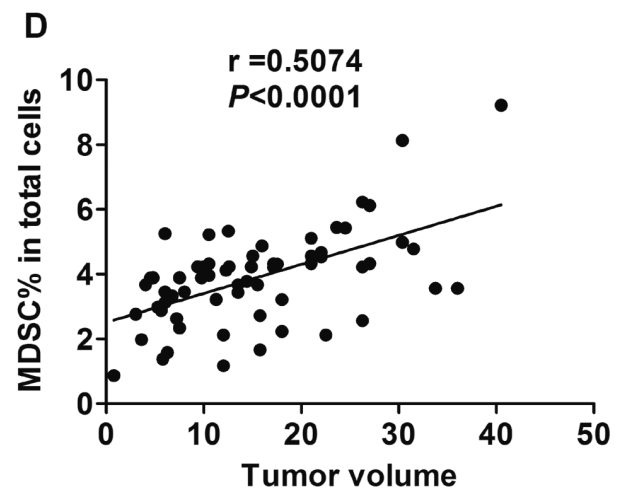

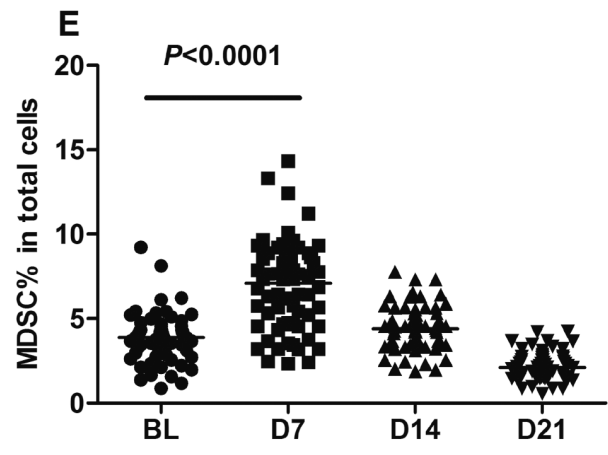

Figure 1. Circulating MDSC percentages in rectal cancer patients and healthy controls. MDSC content was calculated as percentage of total nucleated cells in whole blood samples. Scatter plots of MDSC percentage in (A) healthy donors (HD) vs. cancer patients before operation (BL), (B) well/moderate vs. poor differentiation patients, (C) stage I/II vs. stage III patients, and (D) the correlation between tumor volume ( $\left.\mathrm{cm}^{3}\right)$ and MDSC percentage. (E) Scatter plots of MDSC percentages in patients before operation and at different time points after operation. Bar denotes median in each group. $P<$ 0.05 is considered statistically significant.

effect on T cell proliferation was observed for MDSC from healthy donors $(85.24 \%$ without MDSC versus $84.4 \%$ with MDSC, supplementary Fig1B, $P=0.7311)$. In contrast, MDSCs from cancer patients markedly suppressed the division of autologous $\mathrm{T}$ cells, $80.28 \%$ of $\mathrm{T}$ cells proliferated in the absence of MDSC versus $54.82 \%$ in the presence of MDSC (supplementary Fig1C, $P=0.0026$ ), indicating that the MDSC of cancer patients, but not the MDSC of healthy controls, inhibit $\mathrm{T}$ cell proliferation. This result is consistent with those previous reported [20].

MDSC percentages are positively associated with arginase activity. Next, the mechanism of MDSC-mediated T cell suppression in rectal cancer patients was investigated. Larginine metabolism and its metabolic products are essential for immune-suppressive function of MDSC in cancer-bearing hosts. We investigated the levels of arginase I and NO in peripheral blood samples from rectal cancer patients and healthy donors. There was a significant increase in arginase I levels in rectal cancer patients before surgery as compared with those from healthy controls $(P=0.0003)$. There was a transient increase in arginase I levels in cancer patients after surgery, followed by a decreasing trend $(P=0.0004)$. Plasma NO content was decreased in rectal cancer patients compared to healthy controls. We observe a transient decrease of $\mathrm{NO}$ in cancer patients after operation, followed by gradual increase $(P<0.0001)$. In addition, MDSC percentage was positively correlated with arginase I detection $(\mathrm{r}=0.8026, P<0.0001$ at baseline, $\mathrm{r}=0.7134, P<0.0001$ at day 7 after surgery). The mean pre-operative CEA was $8.56 \pm 7.2 \mathrm{ng} / \mathrm{ml}$ (median, $8.76 \mathrm{ng} / \mathrm{ml}$; ranging from 2.43 to $29 \mathrm{ng} / \mathrm{ml}$ ), which is higher than that in the controls $(P<0.0001)$. To further explore whether there was MDSC qualitative difference in patients' disease course, levels of arginase activity and NO in isolated MDSC cell culture supernatants at different time points were measured. As shown in Fig. 3, the arginase activity in isolated MDSC from patients is higher than that from healthy donors (Fig $3 \mathrm{~A}, P=0.0016)$, the arginase activity at day 7 after surgery is higher than that before surgery (baseline, Fig $3 \mathrm{~B}, P=0.0048$ ), and thereafter a downtrend is shown. MDSC percentages at baseline were positively correlated with arginase activity $(\mathrm{r}=0.8182, P=0.0058$, Fig. $3 \mathrm{C})$, and the MDSC percentages at day 7 after surgery were also positively correlated with arginase activity ( $\mathrm{r}=0.8024, P=0.0073$, Fig. 3D). In contrary to this, NO content in isolated MDSC in healthy donors is higher than that in patients (Fig. 3E). The intracellular NO content at day 7 after surgery is lower than that before sur- 

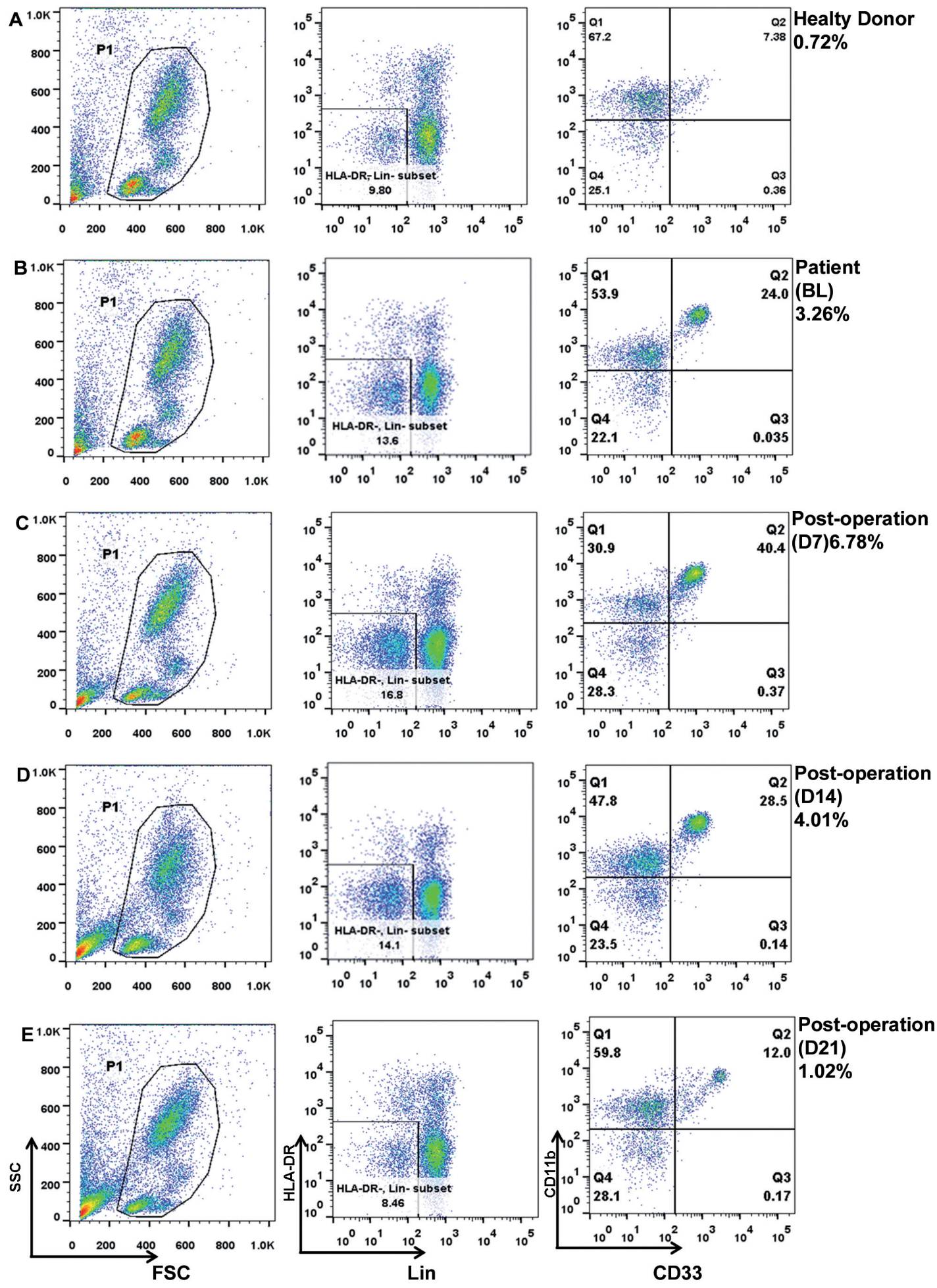

Immunophenotyping of MDSC by flow cytometry

Figure 2. MDSCs definition by flow cytometry. To determine the percentage of MDSCs in patients, fresh whole blood was incubated with a combined anti-Lin, HLA-DR, CD33 and CD11b monoclonal antibodies. Acquired cells were first gated (HLA-DR-/Lin- subset) based on the expression of Lin and HLA-DR. Within this population the fraction of cells expressing both CD33 and CD11b was determined. Therefore, MDSCs were defined as LinHLA-DR-CD33+CD11b+ cells. MDSCs percentage was calculated as percentage of total nucleated cells in whole blood samples. Representative flow cytometric dotplots of a healthy donor (A), a patient with rectal cancer at pre-operation (B), the 7th day after operation(C), the 14th day after operation (D) and the 21st day after operation (E). 

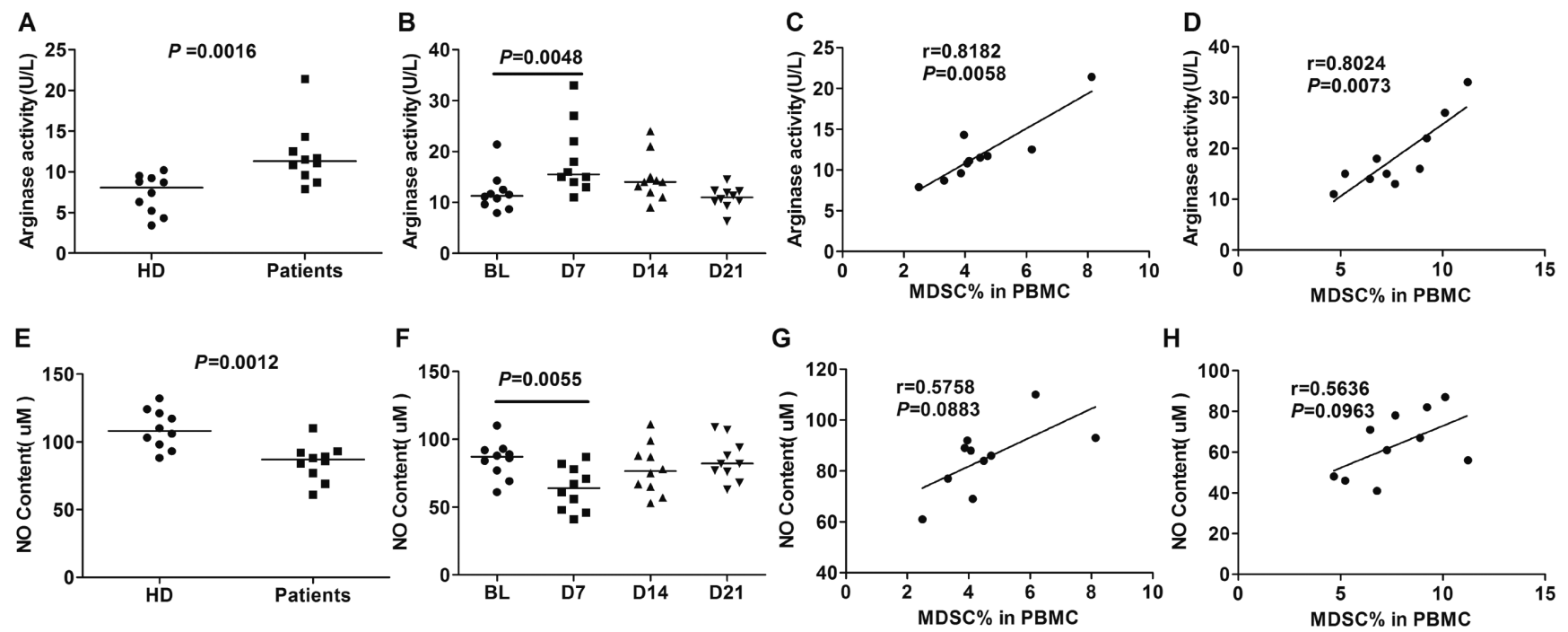

Figure 3. Arginase activity and NO levels in isolated MDSC from PBMC of cell culture supernatants from 10 healthy donors and 10 rectal cancer patients with stage III. (A, E) Scatter plots of arginase activity and NO in the supernatant of isolated MDSC from healthy donors and patients. (B, F) Scatter plots of arginase activity and NO in the supernatant of isolated MDSC in MDSC isolated at different points in the patients' disease course. Correlations of MDSC percentage at baseline with arginase activity (C) and NO content (G). Correlations of MDSC percentage at day 7 after surgery with arginase activity $(\mathrm{D})$ and $\mathrm{NO}$ content $(\mathrm{H})$. Bar denotes median in each group. $\mathrm{P}<0.05$ is considered statistically significant.

gery (baseline, $P=0.0055$, Fig. 3F). There was no correlation between the MDSC percentage and NO content (Fig 3G at baseline and Fig $3 \mathrm{H}$ at day 7 after surgery).

Circulating MDSC percentages correlate with local recurrence. Seven (10.9\%), 15 (23.4\%), and $22(34.4 \%)$ of the 64 cancer patients had local recurrence at the time of $1 \mathrm{yr}, 2$ yrs, and 3 yrs after surgery, respectively. It is discovered in this study that MDSC percentage was slightly higher in patients who recurred 1 year after operation, but the difference was not statistically significant (Fig. 4A). An increase of MDSC percentage at day 21 after operation was also observed in recurrent patients compared to non-recurrence patients (Fig. 4B, $2.39 \%$ versus $1.78 \%, P=0.0393$ ). The pre-operative percentage of MDSC in patients with local recurrence was significantly higher than that in non-recurrent patients (Fig. 4C, $4.22 \%$ versus $3.78 \%, P=0.0323)$. Fourteen of the 31 patients ( $45.16 \%$ ) with elevated pre-operative MDSC had local recurrence at the time of analysis, while only 8 of the 33 patients with lower preoperative percentage of MDSC (24.24\%) had local recurrence (median 3.89\% was used as cut off value). In addition, 13 of the 28 patients (46.43\%) with elevated post-operative percentages of MDSC had local recurrence at the time of analysis, whereas there were only 9 patients (25\%) developed local recurrence in those 36 patients with lower post-operative percentages of MDSC (median 2.21\% was used as cut off value).

We next analyzed the correlation between the MDSC level and distant metastasis. Seven out of the 64 (10.9\%) cases had distant metastasis at the time of analysis. Fig. $4 \mathrm{D}$ shows a significant increase of MDSC percentage at the time of distant metastasis compared to the percentage of day 21 MDSC after operation $(P=0.0175)$. But, there was no significant difference of MDSC percentage at the time of distant metastasis compared to the level of baseline $(P=0.5221$, Fig. 4E).

MDSC percentage is an independent prognostic factor in rectal cancer. To examine whether MDSC percentage could be a prognostic indicator, the 64 patients were divided into two groups by cutoff value based on median percentage. Four of the $64(6.25 \%)$ cancer patients died at the time of analysis. Median follow-up for remaining patients was 42 months (ranging from 10 to 47 months). Patients with high MDSC percentage at baseline had lower disease-free survival (DFS) compared to the patients with low MDSC percentage $(P=0.0357$, Fig. $4 \mathrm{~F})$, and patients with high MDSC percentage at day 21 had lower DFS compared to the patients with low MDSC percentage at day $21(P=0.0460$, Fig. $4 \mathrm{G})$. In addition, patients with high MDSC percentage at baseline had lower local recurrence free survival compared to the patients with low MDSC percentage at baseline $(P=0.0368$, Fig. $4 \mathrm{H})$, and patients with high MDSC percentage at day 21 had lower local recurrence free survival compared to the patients at day 21 with low MDSC percentage ( $P=0.0427$, Fig. $4 \mathrm{I})$. Next we analyzed the correlation between clinicopathological parameters and DFS. As shown in Table 2, pre-operative MDSC percentage $(P=0.038)$ and CEA $(P=0.012)$ were all significantly associated with poor DFS. The MDSC percentage was strongly associated with local recurrence $(P=0.038)$. There was no evidence that tumor grade, post-operative complications, or subsequent treatment status had any impact on local tumor recurrence in our experimental cohort. 
A
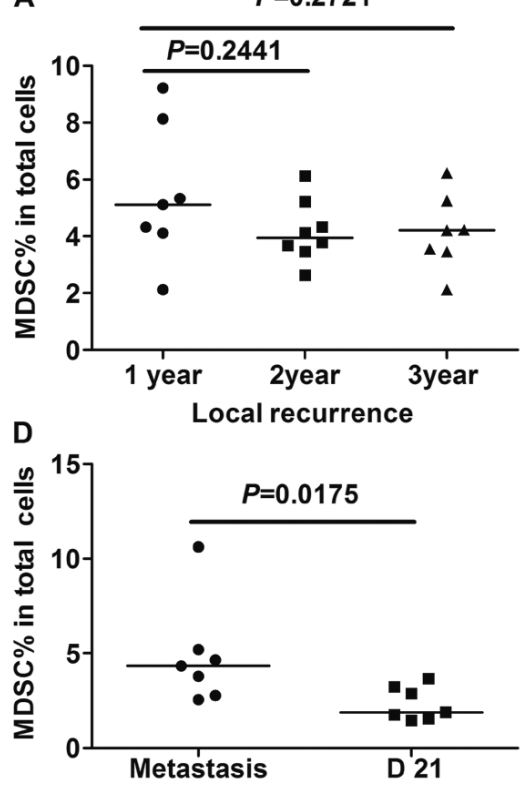

G

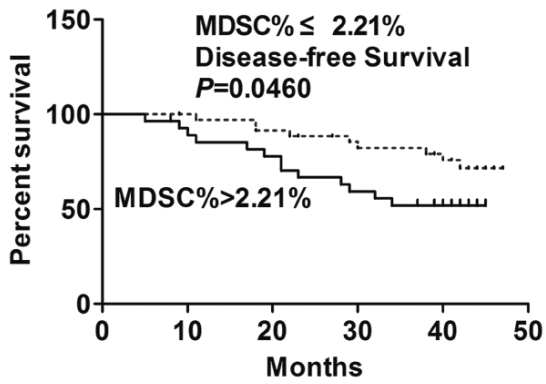

B

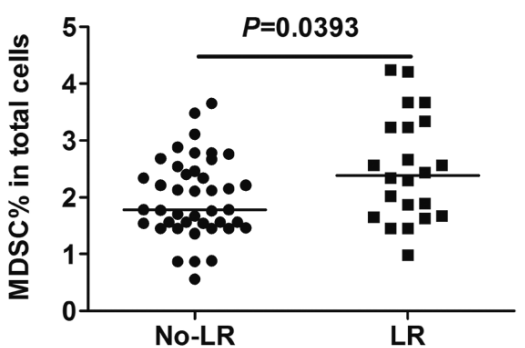

E

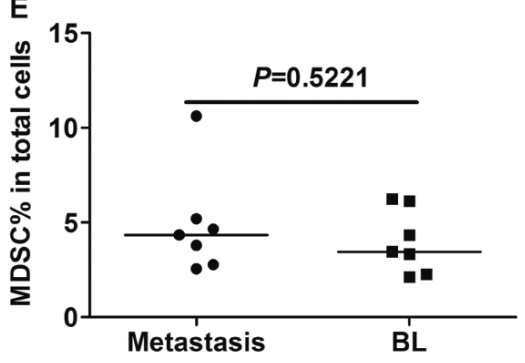

H

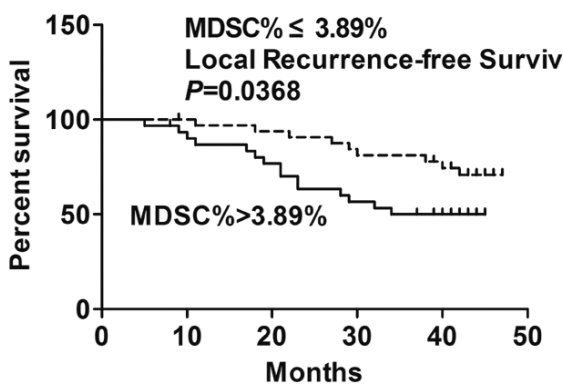

C

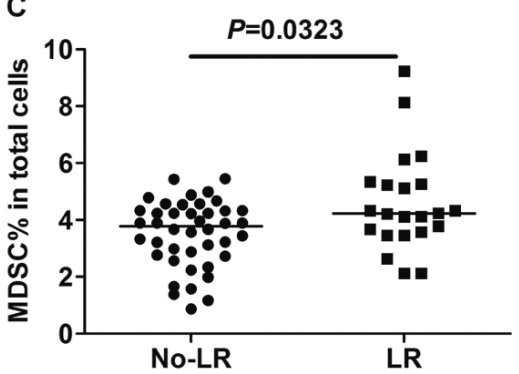

$\mathbf{F}$

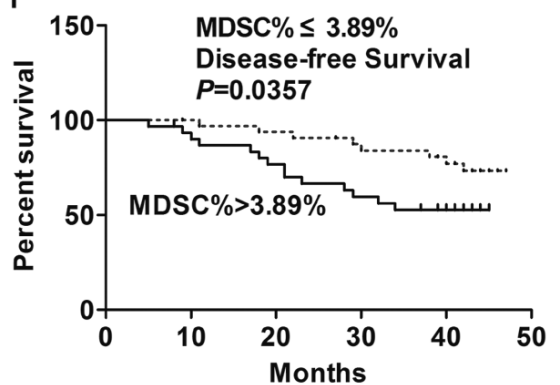

I

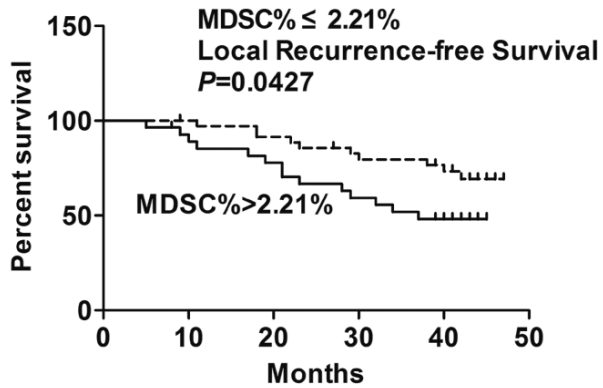

Figure 4. Local recurrence and overall disease-free survival correlation. (A) Scatter plots of pre-operative MDSC percentage in patients who recurred 1 year versus 2 years or 3 years after surgery. (B) Scatter plots of post- operative MDSC percentage at day 21 in local recurrent (LR) and non-recurrent patients (No-LR). (C) Scatter plots of pre-operative MDSC percentages in LR and Non-LR patients. (D, E) MDSC percentages in seven patients with distant metastasis at different time points (pre-operation, day 21 after operation, and presence of metastasis). (F) Disease-free survival curves in patients with high $(>3.89 \%)$ vs. low $(\leq 3.89 \%)$ pre-operative MDSC percentages. (G) Disease-free survival curves in patients with high $(>2.21 \%)$ vs. low $(\leq 2.21 \%)$ post-operative MDSC percentages at day 21. (H) Local recurrence-free survival curves in patients with high $(>3.89 \%)$ vs. low $(\leq 3.89 \%)$ pre-operative MDSC percentages. (I) Local recurrence-free survival curves in patients with high $(>2.21 \%)$ vs. low $(\leq 2.21 \%)$ post-operative MDSC percentages at day 21. Bar denotes median in each group.

\section{Discussion}

MDSC are a heterogeneous population of myeloid cell origin capable of inhibiting adaptive and innate immunity [21]. In healthy subjects, MDSC differentiate into dendritic cells, macrophages and granulocytes. MDSC content is elevated under chronic inflammatory conditions such as stress, aging, infections, cancer or autoimmunity [22]. Most of the recent studies suggest that two major human MDSC subsets exist: granulocytic-MDSC and monocytic MDSC [23]. However, standardized and generally accepted immunophenotyping scheme allows for a clear discrimination of human MDSC subsets is currently missing. The levels of general HLA-DR-Lin ${ }^{-}$ $\mathrm{CD}_{3} 3^{+} \mathrm{CD} 11 \mathrm{~b}^{+}$MDSC were analyzed in our study.
MDSC have been reported to be correlated with clinical cancer stage, metastatic tumor burden, and chemotherapy resistance $[24,25]$. Gabitass et al. have recently reported that an elevated level of circulating MDSC in pancreatic, esophageal, and gastric cancers is an independent prognostic factor for survival [26]. In this study, we report significantly higher percentage of circulating MDSC in rectal cancer patients than in normal volunteer subjects. Furthermore, significantly higher percentage of MDSC was observed in clinical stage III patients than in the stage I/II patients. However, apparent MDSC percentage overlap was seen in these two groups of patients. This may be explained by tumor burden correlation of MDSC content. As we observed in these patients, MDSC percentage is positively associated with tumor volume. How- 
Table 2. Univariate and multivariate analyses of DFS.

\begin{tabular}{|c|c|c|c|c|}
\hline & Level & Hazard ratio & $95 \% \mathrm{CI}$ & $P$-value \\
\hline \multicolumn{5}{|l|}{ Parameters } \\
\hline Age & 62 years & 1.367 & $0.597-2.856$ & 0.436 \\
\hline Gender & male vs. female & 1.164 & $0.553-2.473$ & 0.634 \\
\hline Histologic differentiation & well/moderate vs. poor & 1.323 & $0.319-3.293$ & 0.215 \\
\hline AJCC stage (2010) & I+II vs. III & 0.812 & $0.168-1.383$ & $0.029^{*}$ \\
\hline Post-operative complications & yes vs. no & 0.711 & $0.277-1.327$ & 0.213 \\
\hline Subsequent treatment status after operation & yes vs. no & 0.165 & $0.034-1.360$ & 0.054 \\
\hline Weight loss & yes vs. no & 0.452 & $0.189-1.313$ & 0.188 \\
\hline Smoking status & yes vs. no & 0.356 & $0.198-1.143$ & 0.072 \\
\hline CEA & $3.5 \mathrm{ng} / \mathrm{ml}$ & 1.392 & $0.274-2.843$ & $0.006^{*}$ \\
\hline $\operatorname{MDSC}(\mathrm{BL})$ & $3.89 \%$ & 0.367 & $0.154-0.879$ & $0.024^{*}$ \\
\hline MDSC at D21 $1^{\text {st }}$ post-operation & $2.21 \%$ & 0.413 & $0.174-0.977$ & $0.044^{\star}$ \\
\hline \multicolumn{5}{|l|}{ Variables } \\
\hline Pathological stage & I+II vs. III & 0.282 & $0.054-1.826$ & 0.076 \\
\hline CEA & $3.5 \mathrm{ng} / \mathrm{ml}$ & 1.388 & $0.254-2.733$ & $0.012^{*}$ \\
\hline $\operatorname{MDSC}(\mathrm{BL})$ & $3.89 \%$ & 0.398 & $0.166-0.952$ & $0.038^{*}$ \\
\hline MDSC at D2 $21^{\text {st }}$ post-operation & $2.21 \%$ & 0.176 & $0.042-1.532$ & 0.062 \\
\hline
\end{tabular}

Cutoff value was selected based on the median value. In univariate analysis, CEA, pathological stage, MDSC (BL), and MDSC at day 21 after surgery are correlated with DFS. In multivariate analysis, both MDSC $(\mathrm{BL})$ and CEA are predictive factors for DFS. $P<0.05^{\star}$ means significant.

ever, it is known as disclosed in the "Staging manual of AJCC and the response evaluation criteria in solid tumors (RECIST 1.1)" [27] that patients in stage I/II may have the similar tumor burden with some stage III patients. The relative content of MDSC detection is higher in our study compared to the previous report [28]. Despite the difference in sample collecting methods, our results are largely in line with these reports. Recently, Zhang B, et.al. [19] investigated tumor infiltrating MDSC in colorectal carcinoma, and found significantly higher percentage and absolute number of tumor-infiltrating MDSC compared with those in matched non-cancerous tissues. It is interesting to know whether circulating MDSC are associated with tumor infiltrating MDSC. Theoretically, tumor infiltrating MDSC may have rather direct clinical consequences since these cells will influence the microenvironment of tumor cells. Therefore, clinical influence of tumor infiltrating MDSC in rectal carcinoma merits further studies.

In Ohki's study [29], the content of circulating MDSC was lower in breast cancer patients after surgery compared to pre-operation subjects, but the exact post-operation date was not reported. Zhu et al [30] used a mouse model to show that surgery induced myeloid cells to MDSC with higher levels of arginase I, an enzyme which depletes arginine. In our study, the most interesting finding is that there was a dramatic MDSC increase in the rectal cancer patients after surgery, and then the MDSC content was gradually reduced, indicating that MDSC induction by surgery $[31,32]$ may be an early event in the post-operation period. This could be explained as following. First, surgical stress induces expansion of MDSC [31]. Tai et al observed an approximately 2.5-fold increase in the proportion of spleen MDSC after surgery compared to non-surgery controls. In our study, about 1.8-fold increase of circulating MDSC was observed on day 7 after surgery compared to the pre-operative percentage. Second, psychological stress is associated with altered MDSC content [32].. Third, surgery generally induces physical trauma to patients resulting in inflammations such as aseptic inflammation and/or bacterial inflammation during the perioperative period. It has been demonstrated that inflammation could increase apoptosis resistance in MDSC [33-35]. The massive expansion of MDSC after operation indicates that MDSC are poised to be excellent sentinels against infection in the face of systemic stress. In addition, the body secretes many inflammatory cytokines after surgery leading to an immune activation in post-operation individuals. Therefore, inflammatory response may be an alternative mechanism for MDSC expansion in rectal cancer patients.

MDSC exert their immunosuppressive activity through multiple mechanisms [15, 17, 35-37]. In human, arginine is a crucial player in host defense. MDSCs hydrolyze arginine to urea and ornithine with the enzyme arginase, leading to the synthesis of polyamines and proline. In our present study, there was a significant positive correlation between MDSC and arginase $\mathrm{I}$ in rectal cancer patients during the period of perioperative.

We also measured the arginase activity and NO levels in the MDSC culture supernatants from MDSC collected at different time points. As we have verified in our present study that arginase activity at day 7 after surgery is significanly higher than that 
before surgery (baseline), and then gradually reduced. However, NO content in isolated MDSC at day 7 after surgery is lower than that before surgery (baseline). These findings are consistent with the findings for circulating MDSC and NO suggesting that the increased arginase I in MDSC result in depletion of L-arginine, and then NO production in tumors by iNOS metabolization of $\mathrm{L}$-arginine is reduced as well. However, detail molecular mechanism of NO decrease after surgery is still a matter of study. Our in vitro experiment of $\mathrm{T}$-cell suppression verification of tumor MDSC may support the notion that depletion of L-arginine by tumor MDSC plays an important role in immune suppressive function in rectal cancer patients after surgery, although detail molecular mechanism behind this typical tumor MDSC Tcell suppression is to be explored. Many investigators suggest a positive correlation between clinical cancer stage, metastatic tumor burden, and the percentage of MDSC [22, 24, 38, 39]. Elevated MDSC content has been shown to be an independent prognostic factor in some cancers [26]. However, this study shows the difference in pre- and post-operative percentages of circulating MDSC in rectal cancer patients. Local recurrence and survival, the most important endpoints in rectal cancer management [1], were used as the end points in this study. We show that the percentages of MDSC both before surgery and 21 days after surgery correlate with DFS in patients with rectal cancer in univariate analyses. But in the multivariable model, only pre-operative content of MDSC is an independent factor for DFS in rectal cancer patients. Therefore, our results imply that a strong surgical trauma can result in a transient induction of MDSC caused by the increase in arginase I and then resulted in L-arginine depletion. However, the higher MDSC percentage (median $2.21 \%$, range from $0.56 \%$ to $4.24 \%$ ) observed on day 21 after surgery compared to the normal controls (median $0.57 \%$, ranging from $0.32 \%$ to $1.21 \%$ ) may be due to pathological response to local recurrence and this deserves further investigations.

The induction and reduction of MDSC content during early and late post-operations in rectal cancer patients may imply that operation-induced MDSC is reversible, characterizing the clinical significance of MDSC in rectal cancer may provide clues for novel treatment modalities in conjunction with surgical operation.

Alternatively, immune therapy holds promise as a treatment option in perioperative therapy. Understanding the MDSCmediated systemic immune suppression during perioperative period would benefit development of cancer therapeutics and management of adverse side effects.

Supplementary information is available in the online version of the paper.

Acknowledgments: This study is financially supported by $\mathrm{Na}-$ tional Natural Science Foundation of China(grant number 81001212) and a grant from the Henan Medical Science and Technique Foundation(grant number 201001013). The authors thank The Central Laboratory of Affiliated Cancer Hospital, Zhengzhou University for providing flow cytometry facilities, Ruihua Fan and Jing Ding for technical assistance, and Hongliang Liu for statistical analysis instruction.

\section{References}

[1] KUNITAKE H, ABBAS MA. Transanal endoscopic microsurgery for rectal tumors: a review. Perm J 2012; 16: 45-50.

[2] SIEGEL R, DESANTIS C, VIRGO K, STEIN K, MARIOTTO A, et al. Cancer treatment and survivorship statistics, 2012. CA Cancer J Clin 2012; 62: 220-241. http://dx.doi.org/10.3322/ caac. 21149

[3] KOSINSKI L, HABR-GAMA A, LUDWIG K, PEREZ R. Shifting concepts in rectal cancer management: a review of contemporary primary rectal cancer treatment strategies. CA Cancer J Clin 2012; 62: 173-202. http://dx.doi.org/10.3322/ caac. 21138

[4] GREEN VL, MICHNO A, STAFFORD ND, GREENMAN $J$. Increased prevalence of tumour infiltrating immune cells in oropharyngeal tumours in comparison to other subsites: relationship to peripheral immunity. Cancer Immunol Immunother 2013; 62: 863-873. http://dx.doi.org/10.1007/ s00262-013-1395-9

[5] FERJANCIC S, GIL-BERNABE AM, HILL SA, ALLEN PD, RICHARDSON P, et al. VCAM-1 and VAP-1 recruit myeloid cells that promote pulmonary metastasis in mice. Blood 2013; 121: 3289-3297. http://dx.doi.org/10.1182/blood-2012-08$\underline{449819}$

[6] SERAFINI P, MECKEL K, KELSO M, NOONAN K, CALIFANO J, et al. Phosphodiesterase-5 inhibition augments endogenous antitumor immunity by reducing myeloidderived suppressor cell function. J Exp Med 2006; 203: 2691-2702. http://dx.doi.org/10.1084/jem.20061104

[7] GABRILOVICH D. I, NAGARAJ S. Myeloid-derived suppressor cells as regulators of the immune system. Nat Rev Immunol 2009; 9: 162-174. http://dx.doi.org/10.1038/nri2506

[8] BRANDAU S, TRELLAKIS S, BRUDEREK K, SCHMALTZ D, STELLER G, et al. Myeloid-derived suppressor cells in the peripheral blood of cancer patients contain a subset of immature neutrophils with impaired migratory properties. J Leukocyte Biology 2011; 89: 311-317. http://dx.doi. org/10.1189/jlb.0310162

[9] MANTOVANI A. The growing diversity and spectrum of action of myeloid-derived suppressor cells. Eur J Immunol 2010; 40: 3317-3320. http://dx.doi.org/10.1002/eji.201041170

[10] MA G, PAN P.Y, EISENSTEIN S, DIVINO CM, LOWELL $\mathrm{CA}$, et al. Paired Immunoglobin-like Receptor-B Regulates the Suppressive Function and Fate of Myeloid-Derived Suppressor Cells. Immunity 2011; 34: 385-395. http://dx.doi. org/10.1016/j.immuni.2011.02.004

[11] OCHOA AC, ZEA AH, HERNANDEZ C, RODRIGUEZ PC. Arginase, prostaglandins, and myeloid-derived suppressor cells in renal cell carcinoma. Clin Cancer Res 2007;13: 721s726s. http://dx.doi.org/10.1158/1078-0432.CCR-06-2197

[12] ALMAND B, CLARK JI, NIKITINA E, VAN BEYNEN J, ENGLISH NR, et al. Increased production of immature myeloid cells in cancer patients. A mechanism of immunosuppres- 
sion in cancer. J Immunol 2001; 166: 678-689. http://dx.doi. org/10.4049/jimmunol.166.1.678

[13] YOUNG MR, NEWBY M, WEPSIC HT. Hematopoiesis and suppressor bone marrow cells in mice bearing large metastatic Lewis lung carcinoma tumors. Cancer Res 1987; 47: 100-105.

[14] BUESSOW SC, PAUL RD, LOPEZ DM. Influence of mammary tumor progression on phenotype and function of spleen and in situ lymphocytes in mice. J Natl Cancer Inst 1984; 73: 249-255.

[15] SEUNG LP, ROWLEY DA, DUBEY P, SCHREIBER H. Synergy between T-cell immunity and inhibition of paracrine stimulation causes tumor rejection. Proc Natl Acad Sci U S A 1995; 92: 6254-6258. http://dx.doi.org/10.1073/ pnas.92.14.6254

[16] CAI W, QIN A, GUO P, YAN D, HU F, et al. Clinical significance and functional studies of myeloid-derived suppressor cells in chronic hepatitis C patients. J Clin Immunol 2013; 33: 798-808. http://dx.doi.org/10.1007/s10875-012-9861-2

[17] WU L, YAN C, CZADER M, FOREMAN O, BLUM JS, et al. Inhibition of PPAR $\gamma$ in myeloid-lineage cells induces systemic inflammation, immunosuppression, and tumorigenesis. Blood 2012; 119: 115-126. http://dx.doi.org/10.1182/ blood-2011-06-363093

[18] SOLITO S, FALISI E, DIZA-MONTERO CM, DONI A, PINTON L, et al. A human promyelocytic-like population is responsible for the immune suppression mediated by myeloidderived suppressor cells. Blood 2011; 118: 2254-2265. http:// dx.doi.org/10.1182/blood-2010-12-325753

[19] ZHANG B, WANG Z, WU L, ZHANG M, LI W, et al. Circulating and Tumor-Infiltrating Myeloid-Derived Suppressor Cells in Patients with Colorectal Carcinoma. PLoS One 2013; 8: e57114. http://dx.doi.org/10.1371/journal. pone. 0057114

[20] GROS A, TURCOTTE S, WUNDERLICH JR, AHMADZADEH M, DUDLEY ME, et al. Myeloid cells obtained from the blood but not from the tumor can suppress T-cell proliferation in patients with melanoma. Clin Cancer Res 2012; 18:5212-5223. http://dx.doi.org/10.1158/1078-0432. CCR-12-1108

[21] SINHA P, CHORNOGUZ O, CLEMENTS VK, ARTRMENKO KA, ZUBAREV RA, et al. Myeloid-derived suppressor cells express the death receptor Fas and apoptose in response to T cell-expressed FasL. Blood 2011; 117: 5381-5390. http:// dx.doi.org/10.1182/blood-2010-11-321752

[22] MUNDY-BOSSE BL, YOUNG GS, BAUER T, BINKLEY E, BLOOMSTON M, et al. Distinct myeloid suppressor cell subsets correlate with plasma IL-6 and IL-10 and reduced interferon-alpha signaling in CD4+ T cells from patients with GI malignancy. Cancer Immunol Immunother 2011; 60: 1269-1279. http://dx.doi.org/10.1007/s00262-0111029-Z

[23] DUMITRU CA, MOSES K, TRELLAKIS S, et al. Neutrophils and granulocytic myeloid-derived suppressor cells: immunophenotyping, cell biology and clinical relevance in human oncology. Cancer Immunol Immunother 2012; 61:1155-1167. http://dx.doi.org/10.1007/s00262-012-1294-5
[24] DIAZ-MONTERO CM, SALEM ML, NISHIMUA MI, LANG S, BRANDAU S. Increased circulating myeloid-derived suppressor cells correlate with clinical cancer stage, metastatic tumor burden, and doxorubicin-cyclophosphamide chemotherapy. Cancer Immunol Immunother 2009; 58: 49-59. http://dx.doi.org/10.1007/s00262-008-0523-4

[25] MEDINA-ECHEVERZ J, FIORAVANTI J, ZABALA M, ARDAIZ N, PRIETO J, et al. Successful colon cancer eradication after chemoimmunotherapy is associated with profound phenotypic change of intratumoral myeloid cells. J Immunol 2011;186: 807-815. http://dx.doi.org/10.4049/ ¡immunol.1001483

[26] GABITASS RF, ANNELS NE, STOCKEN DD, PANDHA HA, MIDDLETON GW. Elevated myeloid-derived suppressor cells in pancreatic, esophageal and gastric cancer are an independent prognostic factor and are associated with significant elevation of the Th2 cytokine interleukin-13. Cancer Immunol Immunother $2011 ; 60$ : 1419-1430. http://dx.doi.org/10.1007/ s00262-011-1028-0

[27] EISENHAUER E.A, THERASSE P, BOGAERTS J, SCHWARTZ LH, et al. New response evaluation criteria in solid tumors: Revised RECIST guideline (version1.1). Eur J Cancer 2009; 45: 228-247. http://dx.doi.org/10.1016/j. ejca.2008.10.026

[28] DUFFY A, ZHAO F, HAILE L, GAMREKELASHVILI J, FIORAVANTI S, et al. Comparative analysis of monocytic and granulocytic myeloid-derived suppressor cell subsets in patients with gastrointestinal malignancies. Cancer Immunol Immunother 2013; 62: 299-307. http://dx.doi.org/10.1007/ s00262-012-1332-3

[29] OHKI S, SHIBATA M, GONDA K, MACHIDA T, SHIMURA $\mathrm{T}$, et al. Circulating myeloid-derived suppressor cells are increased and correlate to immune suppression, inflammation and hypoproteinemia in patients with cancer. Oncol Rep 2012; 28: 453-458.

[30] ZHU X, HERRERA G, OCHOA JB. Immunosupression and infection after major surgery: a nutritional deficiency. Crit Care Clin 2010; 26: 491-500. http://dx.doi.org/10.1016/j. ccc.2010.04.004

[31] TAI LH, DE SOUZA CT, BELANGER S, LY L, ALKAYYAL AA, et al. Preventing post-operative metastatic disease by inhibiting surgery-induced dysfunction in natural killer cells. Cancer Res 2013; 73: 97-107. http://dx.doi.org/10.1158/00085472.CAN-12-1993

[32] MUNDY-BOSSE BL, THORNTON LM, YANG HC, ANDERSEN BL, CARSON WE. Psychological stress is associated with altered levels of myeloid-derived suppressor cells in breast cancer patients. Cell Immunol 2011; 270: 80-87. http://dx.doi. org/10.1016/j.cellimm.2011.04.003

[33] CHORNOGUZ O, GRMAI L, SINHA P, ARTEMENKO KA, ZUBAREV RA, et al. Proteomic pathway analysis reveals inflammation increases myeloid-derived suppressor cell resistance to apoptosis. Mol Cell Proteomics 2011; 10: M110.002980.

[34] HAVERKAMP JM, CRIST SA, ELZEY BD, CIMEN C, RATLIFF TL. In vivo suppressive function of myeloidderived suppressor cells is limited to the inflammatory site. 
Eur J Immunol 2011;41: 749-759. http://dx.doi.org/10.1002/ eji.201041069

[35] CUENCA AG, DELANO MJ, KELLY-SCUMPIA KM, MORENO C, SCUMPIA PO, et al. A paradoxical role for myeloid-derived suppressor cells in sepsis and trauma. Mol Med 2011; 17: 281-292. http://dx.doi.org/10.2119/ molmed.2010.00178

[36] MOVAHEDI K, GUILLIAMS M, VAN DEN BOSSCHE J, VAN DEN BERGH R, GYSEMANS C, et al. Identification of discrete tumor-induced myeloid-derived suppressor cell subpopulations with distinct T cell-suppressive activity. Blood 2008; 111: 4233-4244. http://dx.doi.org/10.1182/blood-2007 $\underline{-07-099226}$
[37] KODUMUDI KN, WOAN K, GILVARY DL,SAHAKIAN E,WEI S, et al A novel chemoimmunomodulating property of docetaxel: suppression of myeloid-derived suppressor cells in tumor bearers. Clin Cancer Res 2010;16: 4583-4594. http:// dx.doi.org/10.1158/1078-0432.CCR-10-0733

[38] FILIPAZZI P, HUBER V, RIVOLTINI L. Phenotype, function and clinical implications of myeloid-derived suppressor cells in cancer patients. Cancer Immunol Immunother 2012; 61: 255-263. http://dx.doi.org/10.1007/s00262-011-1161-9

[39] SUN HL, ZHOU X, XUE YF, WANG K, SHEN YF. Increased frequency and clinical significance of myeloid-derived suppressor cells in human colorectal carcinoma. World J Gastroenterol 2012; 18: 3303-3309. 


\title{
Pre- and post-operative evaluation: percentages of circulating myeloid-derived suppressor cells in rectal cancer patients
}

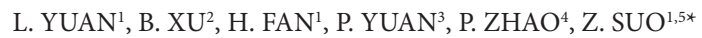

${ }^{1}$ Department of Oncology, The First Affiliated Hospital of Zhengzhou University, Zhengzhou, Henan, P.R. China; ${ }^{2}$ Central Laboratory, The Affiliated Cancer Hospital of Zhengzhou University, Zhengzhou, Henan, P.R. China; ${ }^{3}$ Department of Surgery, The Affiliated Cancer Hospital of Zhengzhou University, Zhengzhou, Henan, P.R. China; ${ }^{4}$ Department of Oncology, The First Affiliated Hospital of Zhejiang University, Hangzhou, Zhejiang, PR, China; ${ }^{5}$ Department of Pathology, Oslo University Hospital and Clinical Institute, Faculty of Medicine, University of Oslo, Oslo, Norway

*Correspondence: zhenhe.suo@medisin.uio.no

Supplementary Figure

A
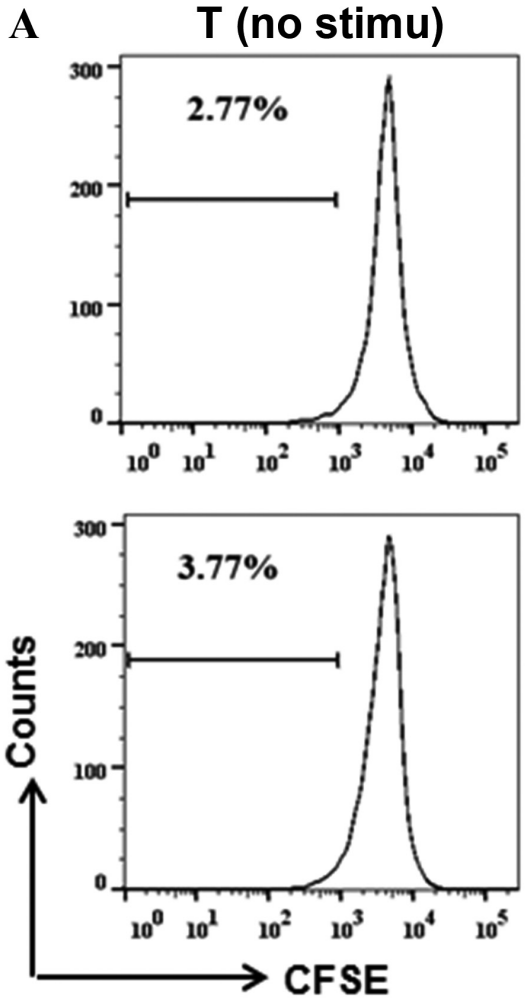

T without MDSC
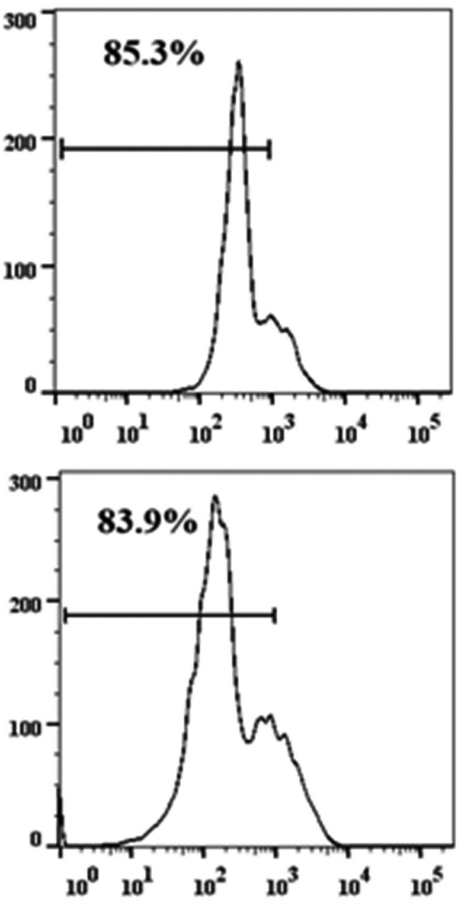

T with MDSC

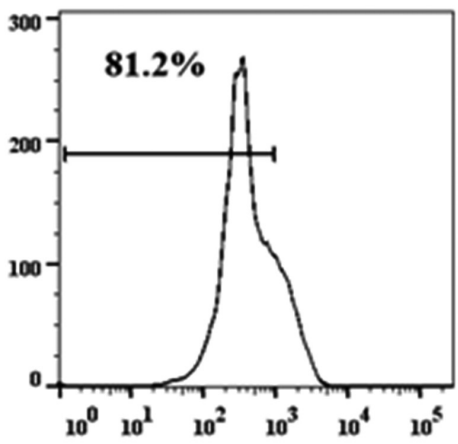

HD

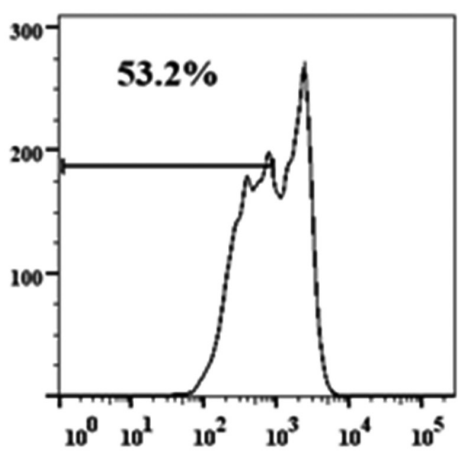


B

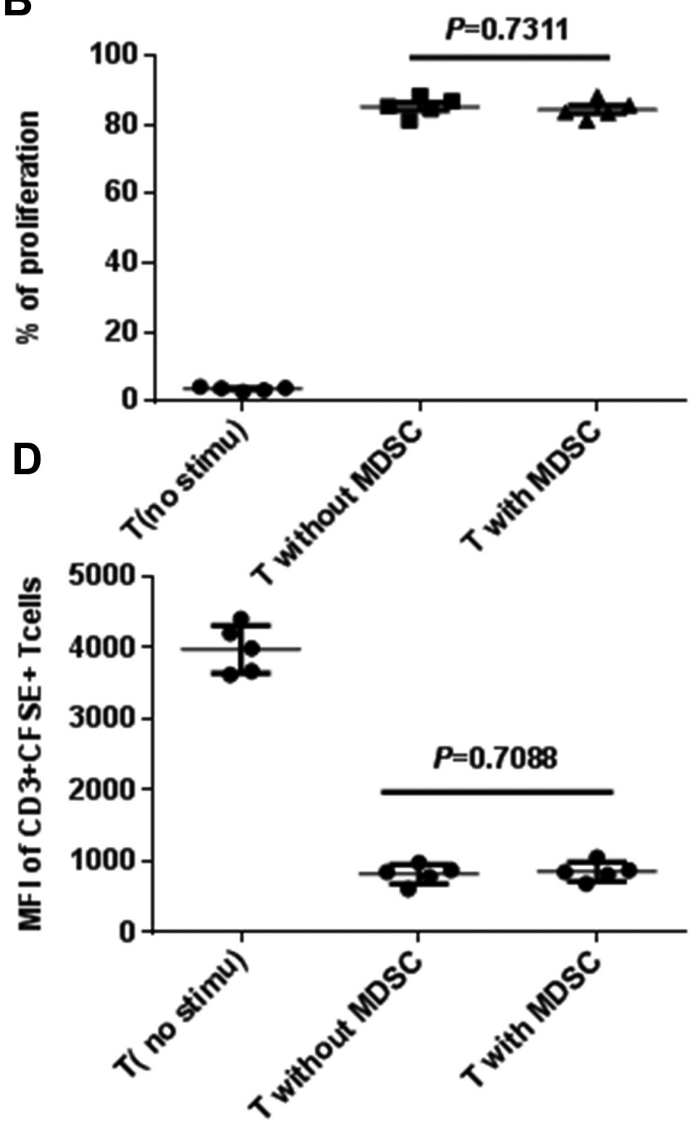

C
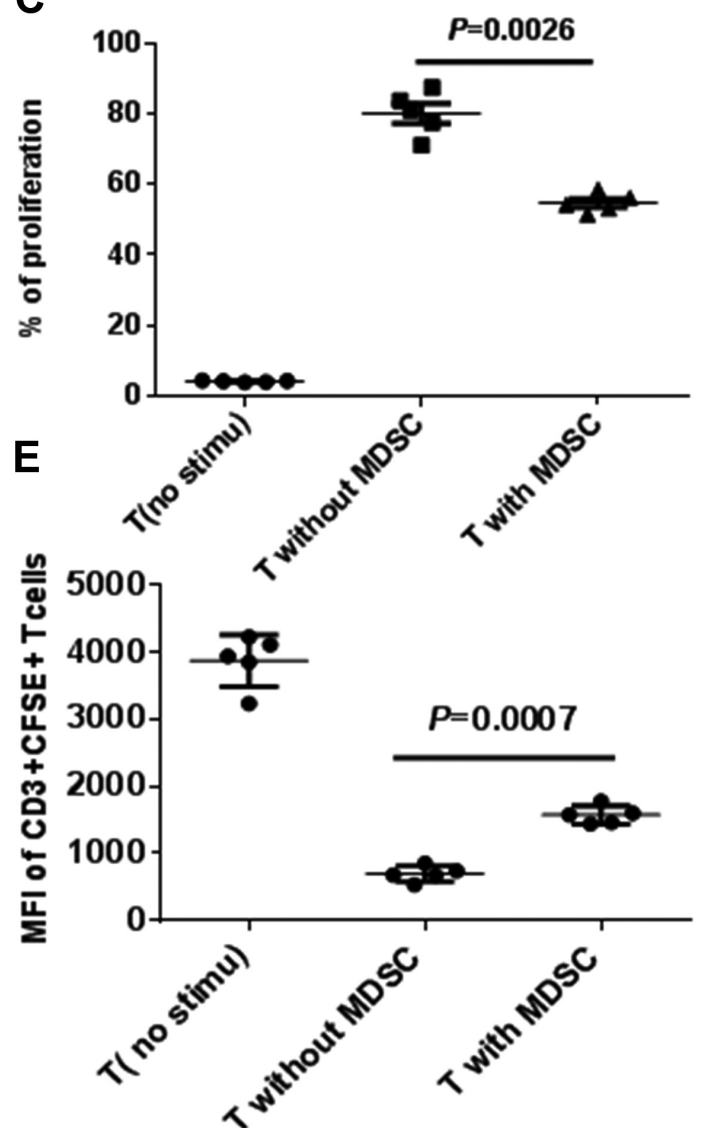

Supplementary Fig S1. MDSC from rectal cancer patients inhibit autologous $\mathrm{CD}^{+}{ }^{+} \mathrm{T}^{-}$-ell proliferation. MDSC (Lin-HLA-DR-CD33 ${ }^{+} \mathrm{CD}^{-} \mathrm{Hb}^{+}$) and autologous $\mathrm{CD}^{+} \mathrm{T}$ cells were sorted from 5 healthy donors and 5 patients with stage III cancer. T cells labeled with CFSE were cultured without autologous MDSC ( $T$ without MDSC) or with autologous MDSC ( $T$ with MDSC) at 2:1 ratio in the absence or presence of anti-CD3/CD28 antibody and IL-2 for 4 days, and unstimulated $\mathrm{T}$ cells were used as negative control. (A) Representative flow cytometry data from one healthy donor (HD) and one cancer patient. Graph shows $\mathrm{CFSE}^{+} \mathrm{CD3}^{+} \mathrm{T}$ cells and the percentage of cells in division. (B) Quantitation from five healthy donors. (C) Quantitation from five

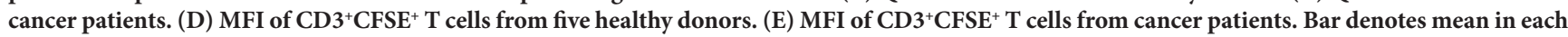
group. $P<0.05$ is considered statistically significant. 


\title{
Pre- and post-operative evaluation: percentages of circulating myeloid-derived suppressor cells in rectal cancer patients
}

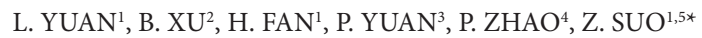

${ }^{1}$ Department of Oncology, The First Affiliated Hospital of Zhengzhou University, Zhengzhou, Henan, P.R. China; ${ }^{2}$ Central Laboratory, The Affiliated Cancer Hospital of Zhengzhou University, Zhengzhou, Henan, P.R. China; ${ }^{3}$ Department of Surgery, The Affiliated Cancer Hospital of Zhengzhou University, Zhengzhou, Henan, P.R. China; ${ }^{4}$ Department of Oncology, The First Affiliated Hospital of Zhejiang University, Hangzhou, Zhejiang, PR, China; ${ }^{5}$ Department of Pathology, Oslo University Hospital and Clinical Institute, Faculty of Medicine, University of Oslo, Oslo, Norway

*Correspondence: zhenhe.suo@medisin.uio.no

Supplementary Figure

A
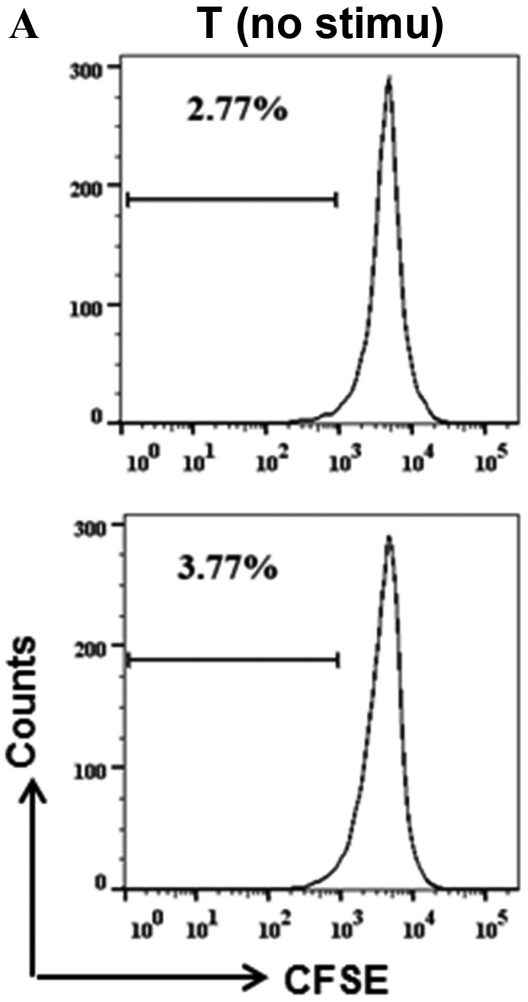

T without MDSC
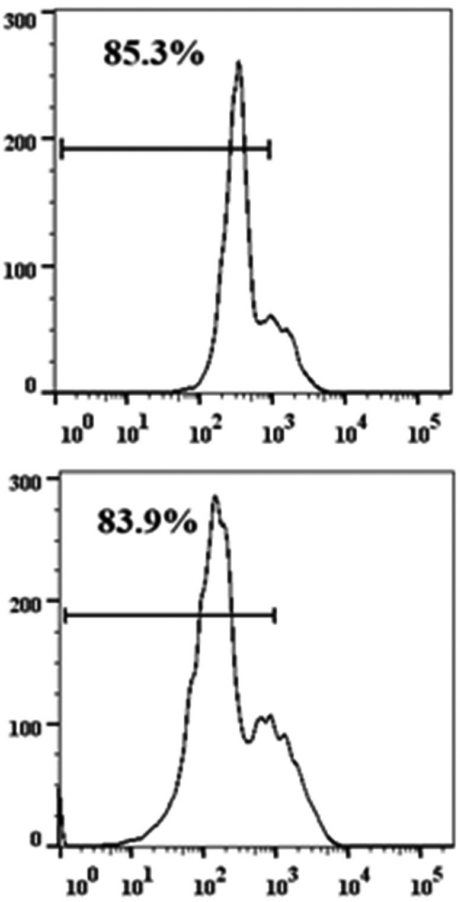

T with MDSC

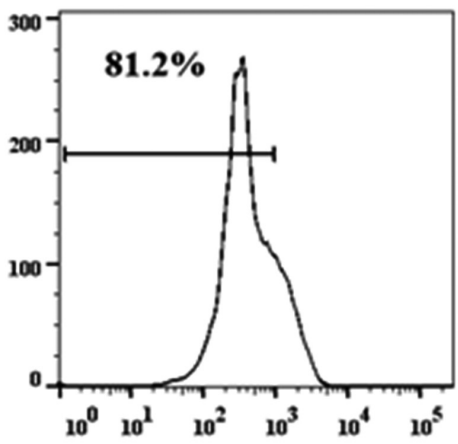

HD

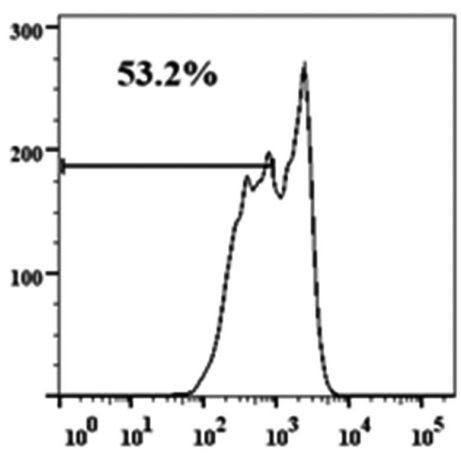


B

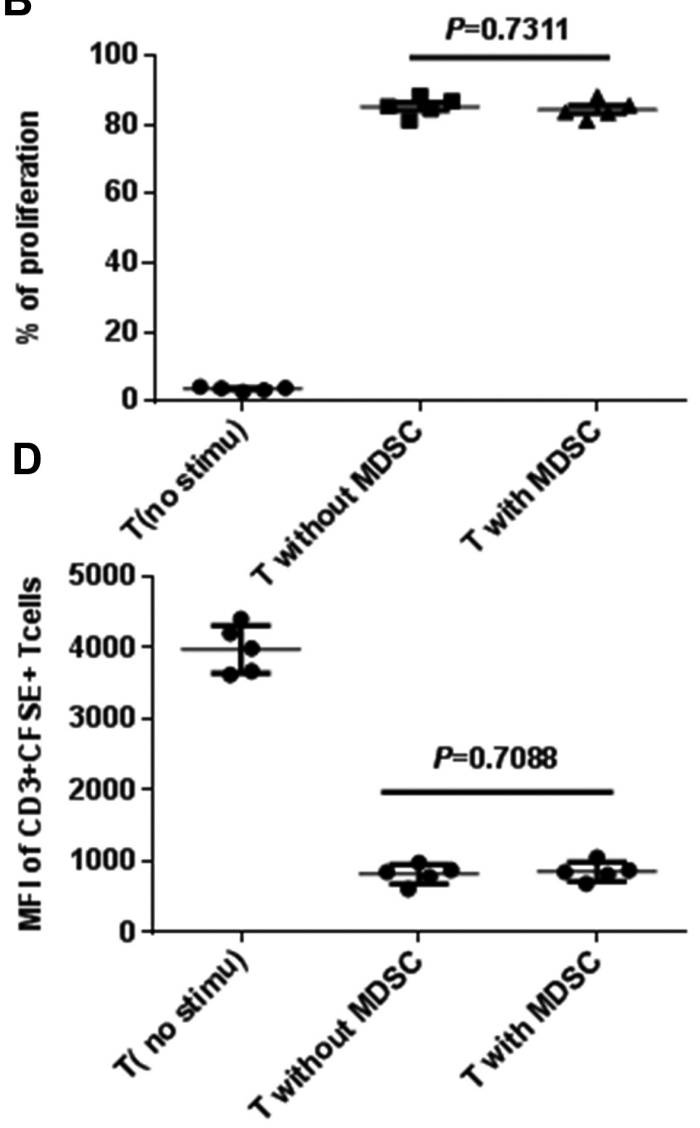

C
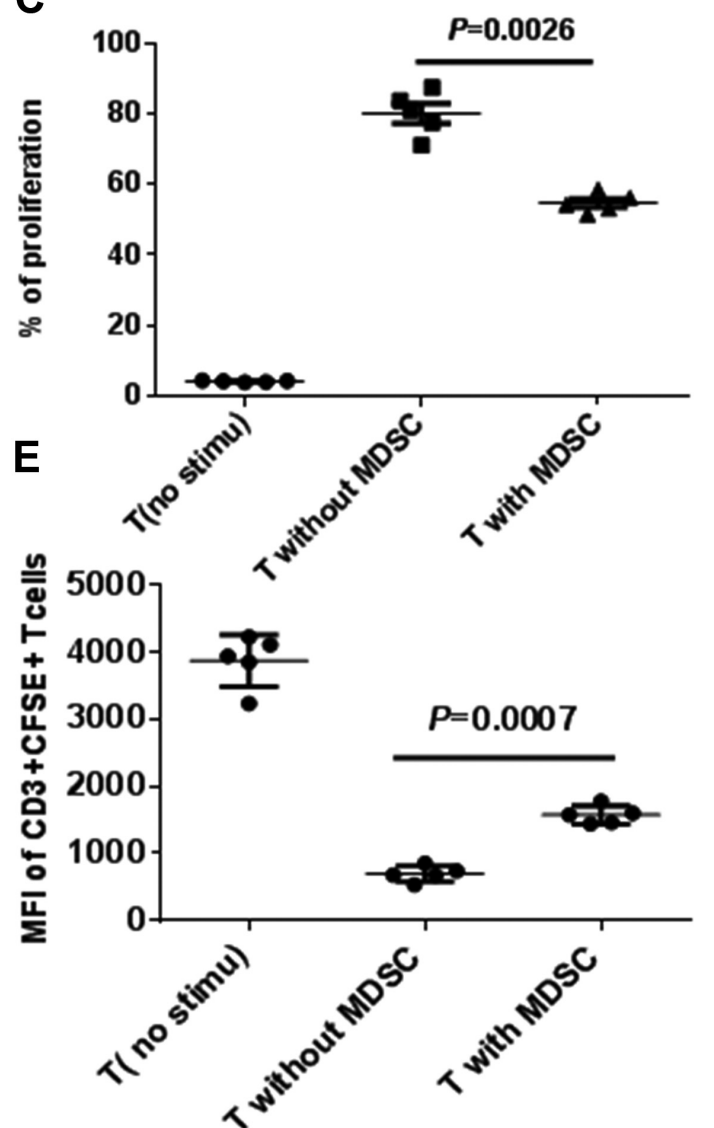

Supplementary Fig S1. MDSC from rectal cancer patients inhibit autologous $\mathrm{CD}^{+}{ }^{+} \mathrm{T}^{-}$-ell proliferation. MDSC (Lin-HLA-DR-CD33 ${ }^{+} \mathrm{CD}^{-} \mathrm{Hb}^{+}$) and autologous $\mathrm{CD}^{+} \mathrm{T}$ cells were sorted from 5 healthy donors and 5 patients with stage III cancer. T cells labeled with CFSE were cultured without autologous MDSC ( $T$ without MDSC) or with autologous MDSC ( $T$ with MDSC) at 2:1 ratio in the absence or presence of anti-CD3/CD28 antibody and IL-2 for 4 days, and unstimulated $\mathrm{T}$ cells were used as negative control. (A) Representative flow cytometry data from one healthy donor (HD) and one cancer patient. Graph shows $\mathrm{CFSE}^{+} \mathrm{CD3}^{+} \mathrm{T}$ cells and the percentage of cells in division. (B) Quantitation from five healthy donors. (C) Quantitation from five

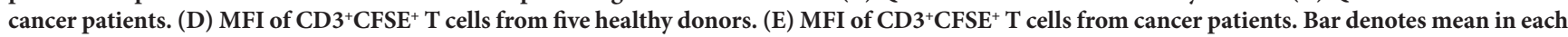
group. $P<0.05$ is considered statistically significant. 